\title{
PERSPECTIVES OF THE LANGUAGES OF RUSSIA IN EDUCATION SPHERE*
}

\author{
Aysa N. Bitkeeva ${ }^{1 * \star}$, Maria Ya. Kaplunova ${ }^{2}$ \\ ${ }^{1}$ Dr.Sc., Leading Research Fellow, Research Center on Ethnic and Language Relations, Institute \\ of Linguistics of the Russian Academy of Sciences; Leading Research Fellow, A.M. Gorky Institute \\ of World Literature, Russian Academy of Sciences, THE RUSSIAN FEDERATION, \\ aisa bitkeeva@yahoo.com \\ ${ }^{2}$ Ph.D., Research Fellow, Research Center on Ethnic and Language Relations, Institute of \\ Linguistics of the Russian Academy of Sciences; Assistant Professor, Moscow State Pedagogical \\ University, THE RUSSIAN FEDERATION, mary.golik@gmail.com \\ ${ }^{* *}$ Corresponding Author
}

\begin{abstract}
The article analyses theoretical and practical significance of language prognosis as an instrument of language policy and planning develops concepts in the language scenario field in the sphere of education. The object of the research is the languages of the Russian Federation in the sphere of education.

In general, the research question of the article addresses the future of multilingualism in the Russian Federation, with a focus on the sphere of education. The objective of the article is to systematically explore the foundations for prognostic models and methods in the selected fields of language policy. We aim to develop an interdisciplinary approach to sociolinguistic prognosis on the basis of the future scenario method and, thus, to work out prognostic models and methods in language policy considering their effectiveness in regard to the language policy and planning. Furthermore, we seek to demonstrate their applicability on the basis of the language situation of the Russian Federation. In doing so, we elaborate strategies and derive from the prognostic models recommendations for the language policy in the Russian Federation, a country with an unprecedented language diversity on the Eurasian continent.
\end{abstract}

Compared to the post-Soviet period, current language processes and language development in the changing Russia have been investigated, but the subjects are limited. The need for research in this area is explained by many country-specific reasons. First, it is the acceleration of minority languages' disappearance rate: at the beginning of the 20th century the position of minority languages in Russia was considered more satisfactory than in many countries of the world (Australia, the USA, etc.), while now they are all in varying stages of language shift. Second, the functional distribution between Russian and the national / minority languages is changing nowadays. Third, the recent amendments to the Federal Law "On the Education in the Russian Federation" adopted in 2018 have significantly changed the educational landscape of Russia. Fourth, there are hot societal debates about the current language policy and its measures.

The theme is of high societal relevance: the development of prognostic methods and models in the language policy of the Russian Federation, taking into account the latest research in this area and the practical experience of other countries, is important for public policy planning and effective regulation of the interethnic relations in the Russian Federation.

Keywords: Language situation, language policy, languages of Russia, sphere of education.

\footnotetext{
* The reported in the article study was funded by RFBR and DFG, project number № 21-512-12002 HHИO_a "Prognostic methods and future scenarios in language policy - multilingual Russia as an example".
} 


\section{INTRODUCTION}

Linguists differ very much in their views about managing the great problem of linguistic endangerment [Wurm, 1997]. Some of them stress the possibility of saving endangered languages by active actions and by means of proper decision-making, whereas other linguists are more pessimistic and consider endangerment to be only a linguistic problem, thus, ignoring its extralinguistic aspect. They regard language endangerment as an inevitable natural phenomenon in the evolution of languages and consider saving languages is not worth trying, because finally there will be a single dominant language left in the future (English, for instance) [Kraus, 1997; Ladefoged, 1992].

However, we claim that the language of every ethnos, even the smallest one, is of such a unique cultural value that it must necessarily be the object of active protection and safeguarding. In this respect, a linguistic portrait of the Russian Federation is very representative. At present, Russia is a rapidly developing country and is unique for a great number of reasons, including not only its multiethnic and multilingual populations but also its diverse cultural traditions.

According to the administrative system of the Russian Federation it is made up of eighty-five federal subjects, including ethnically defined administrative units, i.e. republics (twenty-two), and territorial administrative units; i.e. krays (nine), okrugs, or districts (four), oblasts (forty-six), one autonomous oblast, and three cities of federal significance (Moscow, Saint Petersburg, and Sevastopol).

Russia is a multi-ethnic state, the basis of which is formed by 176 national groups and a similar number of languages. The languages functioning within the Federation belong to different language families: Slavic, Turkic, Finno-Ugric, Caucasian, Mongolian and others. It is quite natural that they exist at different levels of development. Some of these languages have a long written tradition, others have a more recent one, while most of them have no written tradition, they have been and are still being severely endangered. Many of the ethnic languages of Russia have been proclaimed national languages of the respective republics.

The national policy of Russia has always been oriented towards the solution of two interrelated tasks: the one of building a unified state with an effective system of centralized management and the one of consolidation of the whole population into a supra-ethnic nation with the Russian language as the main integrating factor. This tendency, however, repeatedly came into collision with the tendency of strengthening of the political independence of ethnic regions.

The theme of the development of languages within the system of education of the Russian Federation is of high societal relevance: the use of the ethnic languages in education is of primary importance for the identity of the ethnic groups living on the territory of Russia. Besides, the development of prognostic methods and models in the language policy of the Russian Federation, taking into account the latest research in this area and the practical experience of other countries, is important for public policy planning and effective regulation of the interethnic relations in the Russian Federation.

The reported in the article study was funded by RFBR and DFG, project number № 21-512-12002 HHИO_a "Prognostic methods and future scenarios in language policy - multilingual Russia as an example".

\section{RESULTS}

\subsection{Legal Status of the Languages of the Russian Federation}

The current language policy in the country is based on the norms of the Constitution of the Russian Federation, as well as on the provisions of the laws "On Languages of the Peoples of the Russian Federation" (1991) and "On the State Language" (2005), implemented through the acts on languages adopted by the republics of the Russian Federation, which define the state status of the thirty-four languages of the peoples of Russia.

According to this legal basis of the Russian Federation the Russian language has been granted the status of a state language (Constitution of the Russian Federation, 1993; Federal Law "On the State Language", 2005). With the latest amendments to the Constitution it is also described as "a language of a state-building nation, alongside with other ethnic groups enjoying equal rights and forming the multinational union of the Russian Federation" (Federal Law on amendments to Russian Federation Constitution, 2020).

In the national-state entities which have the status of the Republics, problems of enhancing ethnic languages 
and cultures are usually more acute. One of the statehood attributes of the Republics, along with the flag, the coat of arms and the constitution, is the official national / state language, proclaimed in the Constitution of the Russian Federation and other corresponding laws (Constitution of the Russian Federation, 1993; Federal Law "On Languages of the Peoples of the Russian Federation",1991).

Thus, in every Republic of the Russian Federation, Russian and titular language(s) are granted a state status. Still, there are some peculiarities in the legislative interpretation of the language in republics. In Altai, for instance, in addition to this, Russian declared "a means of interethnic communication"; in Tuva, Russian and the titular language have an equal status, with the attribute of the former is "the federal language" to substitute for the formula "the state national language".

\subsection{Language Situation in the Russian Federation}

National state bilingualism is quite pertinent as a mode of compromise, that is, the adoption of two national languages in accordance with federal and republican legislation. Still, the UNESCO Atlas of the World's Languages in Danger (formerly known Red Book of Endangered Languages) identifies only three official languages in Russia which are not threatened: Tatar, Yakut and Tuvinian. All other languages are "in the process of extinction" or "endangered" [UNESCO Atlas of the World's Languages in Danger].

The official status of the titular languages of the Republics of the Russian Federation national gives the titular language of a particular republic more possibilities for its functional enhancement, that is, its use in various spheres of communication. This language can also be used (or misused) for political purposes which may lead to linguistic conflicts. This is why processes of language and cultural enhancement in Russia are most complicated in the republics within the Federation.

The main trends of language development in the Russian Federation are as follows:

1) Increased interest in ethnic languages and cultures;

2) Restoration of previous cultural and language traditions;

3) Enhancement of social functions of titular languages;

4) Increased attention to languages of smaller ethnic groups.

This may be interpreted as the extension of the role of these languages, but there is also a discrepancy between their status and functional repertoire. In terms of the revival and promotion of national languages in Russia one may point out a number of facilitating factors, such as the following:

1) Conspicuous efforts on the part of most of the native speakers to expand their functions;

2) Some resources of the previous periods, developed in these languages (published literature including textbooks, monolingual and bilingual dictionaries, grammars etc.);

3) Some experience in teaching these languages as a school subject, as well as their use as languages of instruction;

4) The opening of social perspectives for their use in various areas of communication, given the current status of the state languages in the republics.

At the same time a number of factors that do not contribute to the optimal development of the national languages should be pointed out:

1) A limited use of most of the languages in the areas of public administration, social and political activities, education, mass communication, spiritual culture, and in the service sector;

2) A certain "linguistic nihilism" characteristic of some speakers of the languages in the republics, i.e. their lack of mother tongue competence, as well as lack of interest in acquiring it because of "low social prestige" of these languages;

3) A tendency towards linguistic expansionism manifest in an effort to impose the languages, declared as having a state status, on other language communities in an attempt to exert an influence on them;

4) Deficiencies in the linguistic basis characteristic of the majority of the languages.

Today, there is only one single state language of the Russian Federation - Standard Russian - which meets the requirements associated with high status in every aspect of successfully performing as a state language and also as a language of interethnic communication in the multinational Russian society, instrumental in its 
state-forming, consolidating role.

\subsection{Language Policy and Language Planning in the Russian Federation}

The Russian Federation is a country with age-old traditions in developing ethnic languages and cultures, a country whose peoples cherish their cultural values. In the Soviet period, the major language planning measures were chiefly aimed at promoting the integration processes but there were also trends towards a multi-ethnic society, which served as a topic of investigation among Russian ethnic-linguistic researchers working on legal aspects of multilingual issues, such as linguistic rights both of the individual and the ethnic community. This interest dates back to the 1980s, which was a period of dramatic changes in the Russian society, accompanied by the growing political stance and activity of ethnic groups, aiming at fostering their social and political status.

Every region and republic of the country pursues its language policy, taking into account the particular character of their linguistic situations, their ethnically diverse population, types of settlement, local cultural traditions etc. The acts on languages and other legal norms in the field adopted in the republics repeat the general structure and substantive articles of the "Law on Languages" of the Russian Federation. Thus, they formed the legal basis for bilingualism and multilingualism in the republics, providing, as a rule, for two official languages, namely, a Standard Language and also the language of the respective titular people of the republic. Nevertheless, in some republics, the language situation may be even more diverse; for example, in Kabardino-Balkaria, Dagestan, Mordovia, Karelia, and Yakutia, the laws of which declare these regions as being multilingual. This norm is applied only to the languages of the republics, recognized in accordance with Article 5 of the Constitution of the Russian Federation as state languages, while there is no specification of this kind, as far as krays, autonomous oblasts, or autonomous okrugs are concerned.

\subsection{The Functional Development of the Languages of the Russian Federation in the Sphere of Education}

The use of languages of the Russian Federation in the system of education is proclaimed in the Federal Law "On the Education in the Russian Federation" adopted by the State Duma on December 21, 2012. As stated in Article 5 paragraph 2 of the Law "The right to education in the Russian Federation is guaranteed irrespective of sex, race, nationality, language, origin, property, social and official position, the residence, religion, beliefs, belonging to public associations, and other circumstances" (Federal Law "On the Education in the Russian Federation", 2012). The use of languages is described in the corresponding Article 14 "Language of Education", according to which the basic language of the education is Russian as a state language of the Russian Federation. As stated in Article 14 paragraph 3 of the Law the citizens of the republics (units of the administrative system of Russia with their own official languages) can get the education in the corresponding official language in case the education in these language is not executed "to the detriment of the teaching and learning of the Russian language" (Federal Law "On the Education in the Russian Federation", 2012). Still, the Law lacks any further explanation of the conditions under which the fact of the "detriment" can be proved. Besides, the right for the primary and secondary education in mother tongue is provided to the speakers of other languages of Russia "within the limits of the education system" due to Article 14 paragraph 4 (Federal Law "On the Education in the Russian Federation", 2012).

Amendments of 2018 specified the opportunity for parents or the official representatives if the juvenile to choose the education in mother tongue (this time the opportunity to choose Russian as a mother tongue is granted, thus, providing more teaching hours of Russian for whom it may concern) Federal Law "Concerning the Introduction of Amendments to Articles 11 and 14 of the Federal Law 'On the Education in the Russian Federation"' (2018). The original Law implied no free choice, in fact, the choice of language of instruction was made by the departments of education of the corresponding republics according to the right granted to them in the Constitution of the Russian Federation: "the Republics shall have the right to establish their own state languages" (The Constitution of the Russian Federation, 1993). Still, the amendments of 2018 caused mixed reaction among the citizens of the Republics of Russia and "significantly changed the educational landscape of Russia", providing a certain tension between the language policy de jure and de facto (Bitkeeva, Wingender, 2020: 36).

Another question arising in this context is that in a number of republics (Tuva, Mari El, Adygeya) both the Russian language and titular language competences are required, this practice that caused a wave of discontent among non-titular language speakers, who appealed to the Constitutional Court of the Russian Federation. In its decision the Court confirmed the local authorities' right to require that the population of the republics should have the state language competence, but only after providing the necessary educational activities that will enable everyone in the republic to acquire the "titular" language. 
At present, there are no debates over the importance of the Russian language, spoken almost by everyone, because competence in it is a path to educational opportunities and social mobility across the country. Fluency in Russian, alongside with knowledge of foreign languages, is often seen as a criterion of a person's good education and intelligence. However, for all the prestige of the Russian language there is an understanding that competence in it should not be achieved at the expense of other mother tongues of the citizens of the Russian Federation. The way out of this problem seems to be in seeking optimal solutions allowing an equal use of the languages, the promotion of bilingualism in the republics, as well as in an optimal combination of the functions of the state titular languages and of Russian as the language of allnational importance.

It should also be noted here, though, that most regional languages, now having acquired the status of state languages of the republics, are lacking, for example, sufficiently developed functional styles, hence difficulties arise in using them for the performance of certain public functions; besides, higher education in these languages still remains a goal to be attained due to inadequate development of their terminological systems and of their academic style. Also, the methodological and professional level of titular language instruction, as well as that of the Russian language, is still rather inadequate: the curricula do not meet modern requirements, effective training techniques are absent, and there is a shortage of necessary tutorials and manuals, as well as of qualified teachers. Apparently, these issues are hard to deal with under the conditions of the lack of both special social demand and motivation on the behalf of the state structures in the republics. Still, there is a certain paradox that despite the fact that all of these factors, including appropriate legislation, regulating the functional performance of languages in various spheres of communication are present in the regions, and efforts on a national scale are made to promote motivation so far no radical changes in the linguistic processes have followed. This may be explained by the fact that there is often no language environment outside the schools for pupils and students to develop their speech skills, using their mother tongues in everyday communication.

Of special note are the lesser-used languages of small ethnic groups of Russia that have a minimum of public functions and are not presented in the sphere of education. There is still a slight difference between them because they include languages that are used only in informal communication (Yukagir, Akhvakh, Tazsky, Nenets); others that are used, to a minimum extent, in the areas of organized communication (Veps, Rutul, etc.), and other are used comparatively widely in various areas, such as Abaza. It is known that these languages are in contact with socially more prestigious languages, for example, Aleut, Eskimo, Yukagir, Nivkh, Selkup, and others are used along with Russian. Thus, their relationship is that of functional complementarity, which is an advantage because the speakers of minority languages fulfill in this way their social needs in different areas of communication, but it is also to their disadvantage, because under these circumstances the assimilation of minority languages increases, with some speakers tending to switch entirely to Russian, forgetting their mother tongues.

\section{CONCLUSION}

In general, the research question of the article addresses the future of multilingualism in the Russian Federation, with a focus on the sphere of education. The need for the research in this area is explained by many country-specific reasons. First, it is the acceleration of minority languages' disappearance rate: at the beginning of the 20th century the position of minority languages in Russia was considered more satisfactory than in many countries of the world (Australia, the USA, etc.), while now they are all in varying stages of language shift. Second, the functional distribution between Russian and the titular / minority languages is changing nowadays. Third, the recent amendments to the Federal Law 'On the Education in the Russian Federation' adopted in 2018 have significantly changed the educational landscape of Russia. Fourth, there are hot societal debates about the current language policy and its measures.

The theme is of high societal relevance: the development of prognostic methods and models in the language policy of the Russian Federation, taking into account the latest research in this area and the practical experience of other countries, is important for public policy planning and effective regulation of the interethnic relations in the Russian Federation.

Today, in the early twentieth century, the issues and prospects concerning the ethnic groups of the Russian Federation and their languages continue to be discussed. Much has changed in the socio-cultural character of the peoples, but some of their problems persist, including that of the revival of the lesser-used and minority languages, as well as the issues of promoting the titular languages in many national republics where the real linguistic situation is critical. However, slowly but surely, the tendencies towards a greater ethnic awareness and positive trends in saving the language area are growing; the younger generations of the national intellectual class, interested in facilitating their cultures and languages, are stepping onto the scene 
to make a difference. At this point the question arises: what else should be done to support these positive changes? According to the researchers, the building of areas where titular languages may be used should be the main objective, because even speakers with an excellent command of the languages find it difficult to employ their mother tongue competence for real communication needs. Besides, there should be "spatial" language support, i.e. the speakers should be immersed in the information offered in their own languages, including notices, toponyms, advertisements, newspapers, TV, and radio. It is also necessary to create social zones conducive to the use of the mother tongues, including working places, public transportation, and public facilities. All of these recommendations are quite plausible to implement. In other words, what is required at this point is the promotion of languages and their environments, where they can thrive, with mother tongues becoming an integral part of the ethnic groups' life, which is in fact the main factor for their survival.

Thus, by way of conclusion it may be noted that with the civil society growing in the country, the "unified Russian nation", as it is sometimes called, the current linguistic situation is characterized by tendencies towards the increased efforts on behalf of the society to impact the language issues through special legislation. The success at this stage of language planning and language policy measures will depend not only on the implementation of the principles in the field of linguistic rights declared by the state, but also on the willingness of the peoples themselves - the speakers of given languages - to realize their potential functions in various areas of communication, including the educational one.

\section{REFERENCE LIST}

Bitkeeva, A.N., Wingender, M. (2020). Future scenarios in language policy of Russia: conceptual and methodological aspects. Sociolinguistic Studies, no. 1, pp. 34-53 (In Russ.). DOI: 10.37892/27132951-2020-1-1-34-53.

Constitution of the Russian Federation (1993).

Federal Law "Concerning the Introduction of Amendments to Articles 11 and 14 of the Federal Law 'On the Education in the Russian Federation"' (2018)

Federal Law "On the Amendments to Russian Federation Constitution" (2020)

Federal Law "On the Education in the Russian Federation" (2012)

Federal Law "On the State Language" (2005)

Krauss, M. (1997): The indigenous languages of the North: report on their present state. In: Hiroshi, S., \& Juha, J. (eds.): Northern minority languages: problems of survival. Senri Ethological Studies, no. 44, pp. 1-34.

Ladefoged, P. (1992): Another view of endangered languages. Language, Vol. 68, No. 4: 809-811, Baltimore.

UNESCO Atlas of the World's Languages in Danger, URL: http://www.unesco.org/new/en/culture/themes/endangered-languages/atlas-of-languages-in-danger/

Wurm, S. A. (1997): Prospects of language preservation in the North. In: Hiroshi, S., \& Juha, J. (eds.): Northern minority languages: problems of survival. Senri Ethological Studies, no. 44, pp. 35-53. 